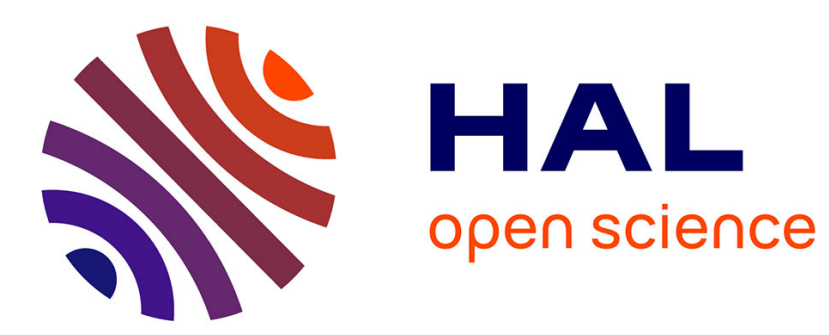

\title{
A sine finite element using a zig-zag function for the analysis of laminated composite beams \\ P. Vidal, O. Polit
}

\section{To cite this version:}

P. Vidal, O. Polit. A sine finite element using a zig-zag function for the analysis of laminated composite beams. Composites Part B: Engineering, 2011, 42 (6), pp.1671-1682. 10.1016/j.compositesb.2011.03.012 . hal-01366932

\section{HAL Id: hal-01366932 \\ https://hal.science/hal-01366932}

Submitted on 5 Jan 2018

HAL is a multi-disciplinary open access archive for the deposit and dissemination of scientific research documents, whether they are published or not. The documents may come from teaching and research institutions in France or abroad, or from public or private research centers.
L'archive ouverte pluridisciplinaire HAL, est destinée au dépôt et à la diffusion de documents scientifiques de niveau recherche, publiés ou non, émanant des établissements d'enseignement et de recherche français ou étrangers, des laboratoires publics ou privés. 


\title{
A sine finite element using a zig-zag function for the analysis of laminated composite beams
}

\author{
P. Vidal *, O. Polit \\ LEME EA 4416, Université Paris Ouest, 50 rue de Sèvres, 92410 Ville d'Avray, France
}

\begin{abstract}
A B S T R A C T
This paper deals with the influence of the use of the Murakami's zig-zag function in the sine model for the analysis of laminated beams. The adding of this function introduces a discontinuity of the first derivative of the in-plane displacement with only one more unknown. The kinematics is based on a sine distribution and the transverse displacement remains constant through the thickness. The transverse shear strain is obtained using a cosine function avoiding the use of shear correction factors. A conforming FE approach is carried out using Lagrange and Hermite interpolations. It is important to notice that the number of unknowns is independent of the number of layers. The purpose is to develop a finite element approach with a low computational cost and without numerical pathology.

This study aims at determining the influence of an additional zig-zag function in the Sine model for static and vibration analysis. In this way, mechanical tests for thin/thick laminated and sandwich beams are presented in order to evaluate the capability of this finite element. The results are compared with elasticity or finite element reference solutions in statics and vibration. Both convergence velocity and accuracy are discussed. This finite element yields satisfactory results at a low computational cost.
\end{abstract}

\section{Introduction}

Composite and sandwich structures are widely used in the industrial field due to their excellent mechanical properties, especially their high specific stiffness and strength. Nevertheless, they exhibit complex behavior. In particular, as it is shown in [1], a slope discontinuity on the displacement field occurs at the interface between two perfectly bonded layers. This phenomenon due to the different transverse shear and normal strains of the layers is known as zig-zag effect. Moreover, the equilibrium equations imply that the transverse shear stress is continuous along the thickness.

The aim of this paper is to determine the influence of an additional zig-zag function in the Sine model for static and vibration analysis. This analysis is limited to the elasticity area in relation to small displacements. In this context, we put the emphasis on the necessity to take into account this effect, in particular for thick or highly anisotropic structures.

According to published research, various theories in mechanics for composite or sandwich structures (beams and plates for the present scope) have been developed. The following classification is associated with the dependency on the number of degrees of freedom (dofs) with respect to the number of layers:
- the Equivalent Single Layer approach (ESL): the number of unknowns is independent of the number of layers, but the transverse shear and normal stresses continuity on the interfaces between layers are often violated. The first work for one-layer isotropic plates was proposed in [2]. Then, we can distinguish the classical laminate theory [3] (it is based on the Euler-Bernoulli hypothesis and leads to inaccurate results for composites and moderately thick beams), the first order shear deformation theory ([4], composite laminates [5]), and higher order theories ([6-13] for instance). All these studies are based on a displacement approach, although other approaches are formulated on the basis of mixed formulations [14,15]. It should be noted that the finite element method is also carried out ([16-19]).

- the Layerwise approach (LW): The number of dofs depends on the number of layers. This theory aims at overcoming the ESL shortcoming of allowing discontinuity of out-of-plane stresses on the interface layers, and has the capacity to take into account the zig-zag effect. This approach was introduced in [20,21], and also used in [22-24]. For recent contributions, see [25-29]. The mixed formulation due to $[30,31]$ is also carried out. See also $[13,32,33]$.

In this framework, refined models have been developed in order to improve the accuracy of ESL models avoiding the 
additional computational cost of LW approach. Based on physical considerations and after some algebraic transformations, the number of unknowns becomes independent of the number of layers. Whitney [23] has extended the work of Ambartsumyan [34] for symmetric laminated composites with arbitrary orientation and a quadratic variation of the transverse stresses in each layer. A family of models, denoted zig-zag models, was employed in [35], then in [36-38]. More recently, it was also modified and improved by some authors [39-44] with differentorder kinematics assumptions, taking into account the transverse normal strain. The zig-zag effect is included in these approaches by taking into account the interlaminar continuity of the transverse shear stress.

Another way to improve the description of the zig-zag effect has been proposed by Murakami [31]. Murakami introduces only one function through the thickness to describe this phenomenon. So, the computational cost remains low. This function denoted "Murakami's zig-zag function" in [45] has been included in some existing models. It can concern classical theory as well as higher order theory for approaches based on displacement and mixed formulations [46-53].

These works show that this function is easy to implement and it enhances the performance of the available models.

This above literature deals with only some aspects of the broad research activity about models for layered structures and corresponding finite element formulations. An extensive assessment of different approaches has been made in [54-57]. About the particular point of the zig-zag effect, see [1].

In this work, a new finite element for rectangular laminated beam analysis is built, in order to have a low cost tool that is efficient and simple to use. Our approach is associated with the ESL theory. This element is totally free of shear locking and includes a refined shear deformation theory [58] avoiding the use of shear correction factors for laminates. It is based on the sinus model $[58,59]$ which is a simple approach with a low computational cost. The new important feature consists of taking advantage of this efficient approach by adding only one specific function more. This one allows us to take into account the zig-zag effect. So, the deduced model remains simple without numerical pathology, and includes only four generalized unknowns.

As far as the interpolation of these finite elements is concerned our elements are $\mathrm{C}^{0}$-continuous except for the transverse displacement associated with bending which is $\mathrm{C}^{1}$.

In this article, first the mechanical formulation for the present model is described. The associated finite element is given. It is illustrated by numerical tests which have been performed upon various laminated and sandwich beams in statics and vibration. A parametric study is given to show the effects of different parameters such as length-to-thickness ratio and number of degrees of freedom. The accuracy of computations is also evaluated by comparisons with an exact three-dimensional theory for laminates in bending [24] and also two-dimensional finite element computations using commercial finite element software. We put the emphasis on the role of the additional zig-zag function in the framework of the family of Sinus models. In this way, the three following models are compared. Their main features are also recalled:

- the Sinus model (denoted Sin) does not include the zig-zag effect and the continuity of the transverse shear stress.

- the Sinus model including the zig-zag function (denoted Sinzz) does not take into account the continuity of the transverse shear stress.

- the Sinus model with the continuity of the transverse shear stress (denoted Sin-c) using the Heaviside function has the capability to represent the zig-zag effect.

\section{Resolution of the mechanical problem}

\subsection{The governing equations}

Let us consider a beam occupying the domain $\mathcal{B}=[0, L] \times\left[-\frac{h}{2} \leqslant\right.$ $\left.z \leqslant \frac{h}{2}\right] \times\left[-\frac{b}{2} \leqslant x_{2} \leqslant \frac{b}{2}\right]$ in a Cartesian coordinate $\left(x_{1}, x_{2}, z\right)$. The beam has a rectangular uniform cross section of height $h$, width $b$ and is assumed to be straight. The beam is made of $N C$ layers of different linearly elastic materials. Each layer may be assumed to be orthotropic in the beam axes. The $x_{1}$ axis is taken along the central line of the beam whereas $x_{2}$ and $z$ are the two axes of symmetry of the cross-section intersecting at the centroid, see Fig. 1. As shown in this figure, the $x_{2}$ axis is along the width of the beam. This work is based upon a displacement approach for geometrically linear elastic beams.

\subsubsection{Constitutive relation}

Using matrix notations, the one dimensional constitutive equations of an orthotropic material are given by

$$
\left[\begin{array}{l}
\sigma_{11} \\
\sigma_{13}
\end{array}\right]=\left[\begin{array}{ll}
\bar{C}_{11} & 0 \\
0 & \bar{C}_{55}
\end{array}\right]\left[\begin{array}{l}
\varepsilon_{11} \\
\varepsilon_{13}
\end{array}\right] \text { i.e. }[\sigma]=[\bar{C}][\varepsilon]
$$

where we denote: the stress vector $[\sigma]$; the strain vector $[\varepsilon]$. Furthermore, in Eq. (1), constitutive unidimensional laws are given by the elastic stiffness matrix $[\bar{C}]$.

Taking into account the classic assumption $\sigma_{22}=\sigma_{33}=0$ (transverse normal stresses are negligible), the longitudinal modulus is expressed from the three-dimensional constitutive laws by

$\bar{C}_{11}=C_{11}-2 C_{12}^{2} /\left(C_{23}+C_{33}\right)$

where $C_{i j}$ are orthotropic three-dimensional elastic moduli. We also have $\bar{C}_{55}=C_{55}$.

\subsubsection{The weak form of the boundary value problem}

Using the above matrix notation and for virtual displacement $\vec{u}^{*} \in U_{0}^{*}$, the variational principle is given by:

find $\vec{u} \in U$ (space of admissible displacements) such as:

$$
\begin{aligned}
& -\int_{\mathcal{B}}\left[\varepsilon\left(\vec{u}^{*}\right)\right]^{T}[\sigma(\vec{u})] d \mathcal{B}+\int_{\mathcal{B}}\left[u^{*}\right]^{T}[f] d \mathcal{B}+\int_{\partial \mathcal{B}_{\mathcal{F}}}\left[u^{*}\right]^{T}[F] d \partial \mathcal{B}=\int_{\mathcal{B}} \rho\left[u^{*}\right]^{T}[\ddot{u}] d \mathcal{B} \\
& \forall \vec{u}^{*} \in U_{0}^{*}
\end{aligned}
$$

where $[f]$ and $[F]$ are the prescribed body and surface forces applied on $\partial \mathcal{B}_{F}$, and $[-]^{T}$ denotes the transpose of the matrix or vector [-]. $\varepsilon\left(\vec{u}^{*}\right)$ is the virtual strain, and $\rho$ is the mass density.

Eq. (3) is a classical starting point for finite element approximations.

\subsection{The displacement field for laminated beams}

The present model is based on the sine model (denoted Sin) developped in $[60,58,59,61-63]$ for various applications on beams, plates and shells. It is improved by only one additional zig-zag function to take into account the discontinuity of the slope of the in-plane displacement at the interface between two adjacent layers.

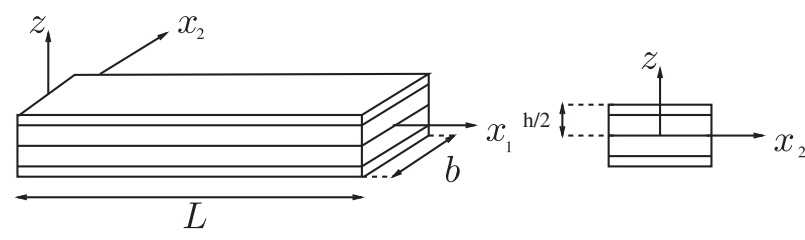

Fig. 1. The laminated beam and coordinate system. 
So, the kinematics of the model (denoted Sinzz) is assumed to be of the following particular form (with $w^{\prime}=\partial w / \partial x_{1}$ ) including the zig-zag function:

For a layer $(k)$

$$
\left\{\begin{aligned}
u_{1}^{(k)}\left(x_{1}, x_{2}, z\right)= & u\left(x_{1}\right)-z w_{0}\left(x_{1}\right)^{\prime}+f(z)\left(\omega_{3}\left(x_{1}\right)+w_{0}\left(x_{1}\right)^{\prime}\right) \\
& +Z_{k}(z) u_{z Z}\left(x_{1}\right) \\
u_{3}\left(x_{1}, x_{2}, z\right)= & w_{0}\left(x_{1}\right)
\end{aligned}\right.
$$

It must be emphasized that only one supplementary function is introduced, associated with the Murakami's zig-zag function $Z_{k}(z)$ which is defined by

$Z_{k}(z)=(-1)^{k} \zeta_{k}(z) \quad$ with $\quad \zeta_{k}(z)=\frac{2}{h_{k}}\left(z-\frac{1}{2}\left(z_{k}+z_{k+1}\right)\right)$

where $h_{k}$ is the thickness of the $k$ th layer while $\left(z_{k}, z_{k+1}\right)$ are the bottom and top coordinates of this layer (see Fig. 3 ). It is obvious that $Z_{k}(z)$ is a piecewise linear function with bi-unit amplitude for all the layers because we have $\zeta_{k}(z) \in[-1,1]$. The physical meaning of the zig-zag term is illustrated in Fig. 2 by comparing the in-plane displacement of the Sin and Sinzz model.

In the classic approach, $w_{0}$ is the bending deflection following the $z$-direction, while $u$ is associated with the uniform extension of the cross-section of the beam along the central line, and $\omega_{3}$ is the shear bending rotation around the $x_{2}$ axis.

In the context of the sine model, we have $f(z)=\frac{h}{\pi} \sin \frac{\pi z}{h}$. This choice can be justified from the three-dimensional point of view, using the work of Cheng [64]. As it can be seen in [65], a sine term appears in the solution of the shear equation (see Eq. (7) in [64]). Therefore, the kinematics proposed can be seen as an approximation of the exact three-dimensional solution. Furthermore, the sine function has an infinite radius of convergence and its Taylor expansion includes not only the third order terms but all the odd terms.

Moreover, the derivative of this function will represent the transverse shear strain distribution due to bending. So, the free boundary conditions at the top and bottom surfaces of the beam are satisfied.

And, it is not necessary to introduce transverse shear correction factors.

Finally, only 3 or 4 generalized displacements are included in Eq. (4) for the Sin and Sinzz model respectively. Note that the Sin-c model is not presented here for brevity reason. It also includes 3 generalized displacements, see [66] for more details.

\subsubsection{Expression of strains}

Matrix notation can be easily defined using a generalized displacement vector as:

$$
\begin{aligned}
& {[u]=\left[F_{u}(z)\right]\left[\mathcal{E}_{u}\right]} \\
& \operatorname{with}\left[\mathcal{E}_{u}\right]^{T}=\left[\begin{array}{llllllll}
u & \vdots & w_{0} & w_{0,1} & \vdots & \omega_{3} & \vdots & u_{\text {ZZ }}
\end{array}\right]
\end{aligned}
$$

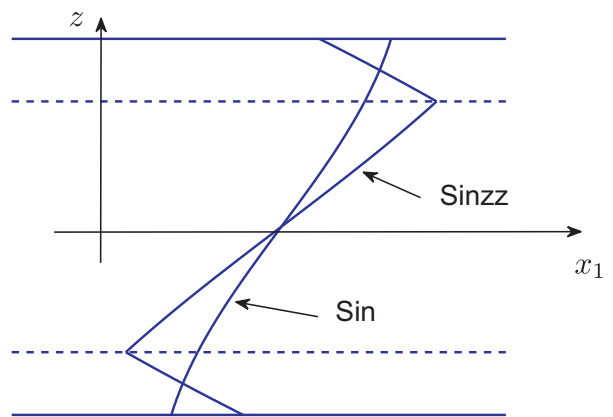

Fig. 2. Inclusion of the zig-zag function to the Sinus model (in-plane displacement).

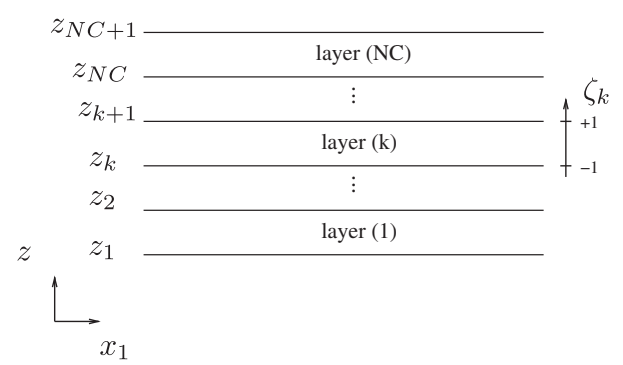

Fig. 3. Transverse coordinate of laminated beam.

and $\left[F_{u}(z)\right]$ depends on the normal coordinate $z$ according to:

$\left[F_{u}(z)\right]=\left[\begin{array}{lllll}1 & 0 & f(z)-z & f(z) & Z_{k}(z) \\ 0 & 1 & 0 & 0 & 0\end{array}\right]$

The strains for the laminated beam are:

$$
\begin{aligned}
\varepsilon_{11}= & u_{, 1}-z w_{0,11}+f(z)\left(\omega_{3,1}+w_{0,11}\right) \\
& +Z_{k}(z) u_{z Z, 1} \\
\gamma_{13}= & f^{\prime}(z)\left(\omega_{3}+w_{0}^{\prime}\right)+Z_{k}^{\prime}(z) u_{z Z}
\end{aligned}
$$

These expressions can be described using a matrix notation:

$[\varepsilon]=\left[F_{s}(z)\right]\left[\mathcal{E}_{s}\right]$ with

$\left[\mathcal{E}_{s}\right]^{T}=\left[\begin{array}{llllllllll}u_{1} & \vdots & w_{0,1} & w_{0,11} & \vdots & \omega_{3} & \omega_{3,1} & \vdots & u_{\mathrm{ZZ}} & u_{\mathrm{ZZ}, 1}\end{array}\right]$

and $\left[F_{s}(z)\right]$ depends on the normal coordinate $z$ as:

$$
\left[F_{s}(z)\right]=\left[\begin{array}{lllllll}
1 & 0 & f(z)-z & 0 & f(z) & 0 & Z_{k}(z) \\
0 & f^{\prime}(z) & 0 & f^{\prime}(z) & 0 & Z_{k}^{\prime}(z) & 0
\end{array}\right]
$$

\subsubsection{Matrix expression for the weak form}

From the weak form of the boundary value problem Eq. (3), and using Eqs. (9), (10) and (6), Eq. (7) , an integration throughout the cross-section is performed analytically in order to obtain an unidimensional formulation. Therefore, the first left and right term of Eq. (3) can be written under the following form:

$$
\begin{aligned}
& \int_{\mathcal{B}}\left[\varepsilon\left(\vec{u}^{*}\right)\right]^{T}[\sigma(\vec{u})] d \mathcal{B}=\int_{0}^{L}\left[\mathcal{E}_{s}^{*}\right]^{T}[k]\left[\mathcal{E}_{s}\right] d x_{1} \text { with } \\
& {[k]=\int_{\Omega}\left[F_{s}(z)\right]^{T}[C]\left[F_{s}(z)\right] d \Omega}
\end{aligned}
$$

and

$$
\begin{aligned}
& \int_{\mathcal{B}} \rho\left[u^{*}\right]^{T}[\ddot{u}] d \mathcal{B}=\int_{0}^{L}\left[\mathcal{E}_{u}^{*}\right]^{T}[m]\left[\ddot{\mathcal{E}}_{u}\right] d x_{1} \text { with } \\
& {[m]=\int_{\Omega} \rho\left[F_{u}(z)\right]^{T}\left[F_{u}(z)\right] d \Omega}
\end{aligned}
$$

where $[C]$ is the constitutive law given in Section 2.1.1, and $\Omega$ represents the cross-section $\left[-\frac{h}{2} \leqslant z \leqslant \frac{h}{2}\right] \times\left[-\frac{b}{2} \leqslant x_{2} \leqslant \frac{b}{2}\right]$.

In Eqs. (11) and (12), the matrices $[k]$ and $[\mathrm{m}]$ are the integration throughout the cross-section of the beam material characteristics.

\subsection{The finite element approximation}

This section is dedicated to the finite element approximation of the generalized displacements, see matrices $\left[\mathcal{E}_{s}\right],\left[\mathcal{E}_{s}^{*}\right],\left[\mathcal{E}_{u}\right]$, and $\left[\mathcal{E}_{u}^{*}\right]$, Eqs. (9) and (6). It is briefly described, and the reader can obtain a detailed description in [59].

\subsubsection{The geometric approximation}

Given the displacement field constructed above for sandwich and laminated beams, a corresponding finite element is developed in order to analyze the behavior of laminated beam structures under combined loads. Let us consider the eth element $L_{e}^{h}$ of the mesh $\cup L_{e}^{h}$. This element has three-nodes, denoted by $\left(g_{j}\right)_{j=1,2,3}$, see Fig. 4 . 


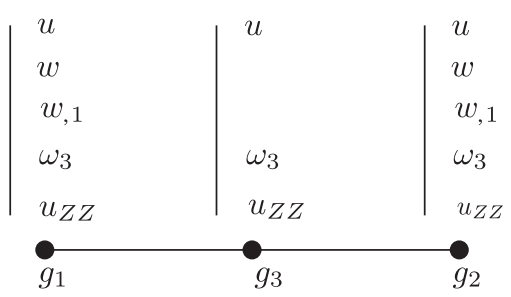

Fig. 4. Description of the laminated beam finite element dof.

A point with coordinate $x_{1}$ on the central line of the beam will be as follows:

$x_{1}(\xi)=\sum_{j=1}^{2} N l_{j}(\xi): x_{1}^{e}\left(g_{j}\right)$

where $N l_{j}(\xi)$ are Lagrange linear interpolation functions and $x_{1}{ }^{e}\left(g_{j}\right)$ are Cartesian coordinates (measured along the $x_{1}$ axis) of the node $g_{j}$ of the element $L_{e}{ }^{h} . \xi$ is an isoparametric or reduced coordinate and its variation domain is $[-1,1]$.

\subsubsection{Interpolation for the bending-traction beam element}

The finite element approximations of the assumed displacement field components are hereafter symbolically written as $u_{i}^{h}\left(x_{1}, x_{2}, z\right)$ where the superscript $h$ refers to the mesh $\cup L_{e}^{h}$.

From the kinematics (see Eq. (4)), the transverse displacement $w^{h}$ must be $C^{1}$ - continuous; whereas the rotation $\omega_{3}{ }^{h}$, the extension displacement $u^{h}$ and $u_{77}^{h}$ can be only $C^{0}$ - continuous. Therefore, the generalized displacement $w^{h}$ is interpolated by the Hermite cubic functions $N h_{j}(\xi)$.

According to the transverse shear locking phenomena, the other shear bending generalized displacements, rotation $\omega_{3}^{h}$, are interpolated by Lagrange quadratic functions denoted $N q_{j}(\xi)$. This choice allows the same order of interpolation for both $w_{1}^{h}$ and $\omega_{3}^{h}$ in the corresponding transverse shear strain components due to bending, and enables to avoid transverse shear locking using the field compatibility approach, see [67].

Finally, traction $u^{h}$ and $u_{z z}^{h}$ are interpolated by Lagrange quadratic functions.

\subsubsection{Elementary matrices}

In the previous section, all the finite element mechanical approximations were defined, and elementary rigidity $\left[K_{u u}^{e}\right]$ and mass $\left[M_{u u}^{e}\right]$ matrices can be deduced from Eqs. (11) and (12). It has the following expression:

$$
\begin{aligned}
& {\left[K_{u u}^{e}\right]=\int_{L_{e}}[B]^{T}[k][B] d L_{e}} \\
& {\left[M_{u u}^{e}\right]=\int_{L_{e}}[N]^{T}[m][N] d L_{e}}
\end{aligned}
$$

where $[B]$ and $[N]$ are deduced from the relation between the generalized displacement vectors Eqs. (9), (6) and the elementary vector of degrees of freedom (dofs) denoted by $\left[q_{e}\right]$ :

$\left[\mathcal{E}_{s}\right]=[B]\left[q_{e}\right] \quad\left[\mathcal{E}_{u}\right]=[N]\left[q_{e}\right]$

The matrices $[B]$ and $[N]$ contain only the interpolation functions, their derivatives and the jacobian components.

The same technique can be used defining the elementary mechanical load vector, denoted $\left[B_{u}^{e}\right]$, but it is not detailed here.

\section{Results and discussions}

In this section, several static and dynamic tests are presented showing the advantages and the limitations of our finite element.

\subsection{Static analysis}

The aim of the present investigation is to study the efficiency of this element to analyze the flexural behavior of highly inhomogeneous sandwich and laminated beams for static mechanical problems. The results are compared with the sinus model (denoted Sin), the sinus model with the heaviside function denoted Sin-c (see [66]), and a reference solution (exact solution [24] or commercial code ANSYS). To evaluate the performance of the element in bending, the considered cases are given in the four following sections.

\subsubsection{Properties of the finite element}

Before proceeding to the detailed analysis, numerical computations are carried out for the rank of the element (spurious mode), convergence properties and the effect of aspect ratio (shear locking).

The test is about simply supported symmetric composite beams. It is detailed below:

Geometry: composite cross-ply beam $\left(0^{\circ} / 90^{\circ} / 0^{\circ}\right)$ and length-to-thickness ratio $S=20\left(S=\frac{L}{h}\right)$; half of the beam is meshed. All layers have the same thickness.

Boundary conditions: simply supported beam subjected to a sinusoidal load $q\left(x_{1}\right)=q_{0} \sin \frac{\pi x_{1}}{L}$.

Material properties:

$$
\begin{aligned}
& E_{L}=172.4 \mathrm{GPa}, E_{T}=6.895 \mathrm{GPa}, G_{L T}=3.448 \mathrm{GPa} \\
& G_{T T}=1.379 \mathrm{GPa}, v_{L T}=v_{T T}=0.25
\end{aligned}
$$

where $L$ refers to the fiber direction, $T$ refers to the normal direction.

This element has a proper rank without any spurious energy modes when exact integration is applied to obtain all the stiffness matrices (see [59]). There is also no need to use shear correction factors here, as the transverse strain is represented by a cosine function.

Table 1 gives the convergence of the Sinzz model for the transverse displacement and the transverse shear stress for $S=20$. For this last component, the results are obtained using the equilibrium equation at the post-processing level i.e. $\sigma_{13}(z)=-\int_{-h / 2}^{z} \sigma_{11,1} d x_{3}$. It must be noticed that the deflection is less sensitive to the mesh than the shear stress and the convergence velocity is very high. Based on progressive mesh refinement, a $N=8$ mesh is adequate to model the laminated beam for a bending analysis. Moreover, the results obtained are in good agreement with the reference values with few elements. In particular, a $N=1$ mesh gives excellent result for the deflection.

Considering various values for aspect ratio, the normalized displacement obtained at the middle of the simply supported composite beam is shown in Fig. 5 along with the exact solution [68], and they are found to be in excellent agreement. It is also inferred from Fig. 5 that the present element is free from shear locking phe-

\begin{tabular}{|c|c|c|c|c|c|c|}
\hline & \multirow[b]{2}{*}{$N$} & \multirow[b]{2}{*}{ Dof number } & \multicolumn{2}{|c|}{$w_{m}=\frac{100 w(L / 2,0) E_{T} h^{3}}{q_{0} L^{4}}$} & \multicolumn{2}{|c|}{$\bar{\sigma}_{13}(0,0)=\sigma_{13} / q_{0}$} \\
\hline & & & & Error (\%) & Equil. Eq & Error (\%) \\
\hline \multirow{5}{*}{ Sinzz } & 1 & 6 & 0.6154 & 0.5 & 5.8068 & 33 \\
\hline & 2 & 12 & 0.6151 & 0.5 & 7.9604 & 9 \\
\hline & 4 & 24 & 0.6151 & 0.5 & 8.5483 & 2 \\
\hline & 8 & 48 & 0.6151 & 0.5 & 8.6988 & 0.5 \\
\hline & 16 & 96 & 0.6151 & 0.5 & 8.7367 & 0.1 \\
\hline Exact & & & 0.6185 & & 8.7483 & \\
\hline
\end{tabular}

Table 1

$\bar{\sigma}_{13}(0,0), w_{m}$ for different number of dofs: mesh convergence study -3 layers $\left(0^{\circ} / 90^{\circ}\right)$ $\left.0^{\circ}\right)-\mathrm{S}=20$. 


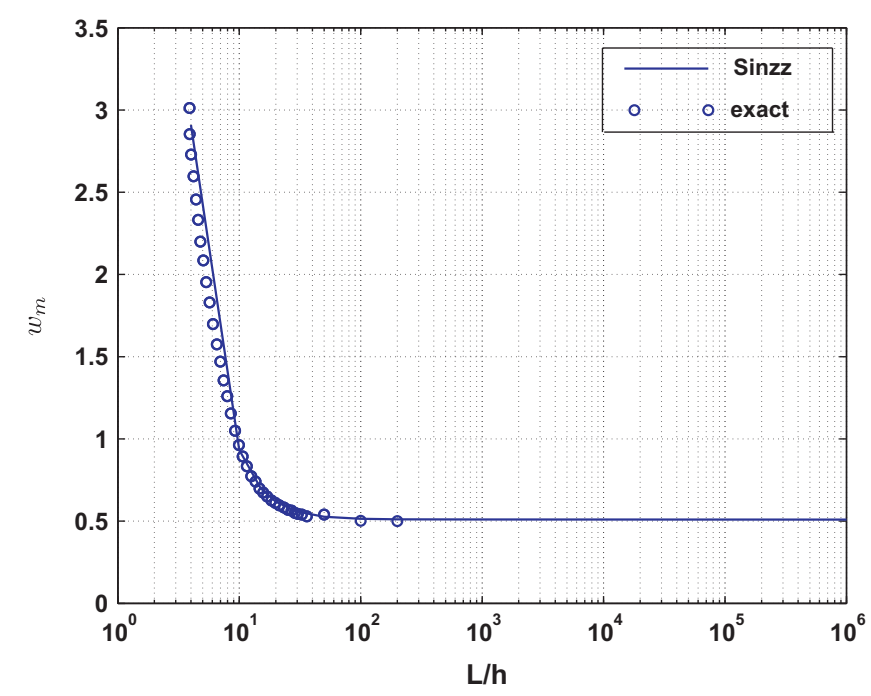

Fig. 5. Variation of the non-dimensional maximum displacement $\left(w_{m}=100 w(L)\right.$ 2,0) $\left.E_{T} h^{3} /\left(q_{0} L^{4}\right)\right)$ with respect to aspect ratio $S$ - three layers $\left(0^{\circ} / 90^{\circ} / 0^{\circ}\right)$; mesh $N=8$ ; Sinzz model.

nomenon as the element is developed using a field compatibility approach.

\subsubsection{Bending analysis of laminated composite beam}

This test is about simply supported symmetric and anti-symmetric composite beams from Ref. [68]. It is detailed below.

Geometry: composite cross-ply beam $\left(0^{\circ} / 90^{\circ} / 0^{\circ}\right)$ and $\left(0^{\circ} / 90^{\circ}\right)$ and length-to-thickness ratio from $S=4$ to $S=40$; half of the beam is meshed. All layers have the same thickness.

Boundary conditions: simply supported beam subjected to a sinusoidal load $q\left(x_{1}\right)=q_{0} \sin \frac{\pi x_{1}}{L}$.

Material properties: same properties as in Section 3.1.1

The two layer case $\left(0^{\circ} / 90^{\circ}\right)$ is first presented. The numerical results for deflection, in-plane displacements, shear stress and in-plane stress are given in Tables 2-4 with respect to the spanto-thickness ratio: $S=4$ (thick), $S=20$ (moderately thick), $S=40$ (thin). The percent error with respect to $S$ for the three models is compared in these tables.

For the displacements, the model including the zig-zag function gives more precise results than the two sinus models (Sin and Sinc). The error is less than $3 \%$ regardless of the length-to-thickness ratio. Concerning the stresses, the improvement is also significant. The maximum error is $6 \%$ for the thick beam. It seems that the influence of the zig-zag function is more important than the continuity of the transverse shear stress, especially for the thick beam. Note that the results of the three models are rather good for $S \geqslant 20$, the maximum error rate is $1.4 \%$.

For $S=4$, the variation of the normalized in-plane stress, transverse shear stress and in-plane displacement through the thickness
Table 3

Comparison between the different Sinus models: without zig-zag effects (Sin), with zig-zag function (Sinzz), and with zig-zag and continuity of the transverse shear stress $\left(\right.$ Sin-c) $-\bar{\sigma}_{13}(0,-h / 4)(\operatorname{maxi})$ for different values of $S-2$ layers $\left(0^{\circ} / 90^{\circ}\right)$.

\begin{tabular}{rrlrlrlr}
\hline \multirow{2}{*}{$S$} & \multicolumn{1}{c}{$\bar{\sigma}_{13}(0,-h / 4)$} & & & & & \\
\cline { 2 - 7 } & \multicolumn{1}{c}{ Sinzz } & Error $(\%)$ & Sin-c & Error (\%) & \multicolumn{1}{l}{ Sin } & Error (\%) & Exact \\
\hline 4 & 2.843 & 5 & 3.057 & 13 & 2.972 & 9.8 & 2.706 \\
20 & 14.574 & 0.3 & 14.684 & $<0.1$ & 14.602 & 0.1 & 14.620 \\
40 & 29.174 & 0.5 & 29.197 & 0.4 & 29.180 & 0.4 & 29.325 \\
\hline
\end{tabular}

Table 4

Comparison between the different Sinus models: without zig-zag effects ( $\operatorname{Sin})$, with zig-zag function (Sinzz), and with zig-zag and continuity of the transverse shear stress (Sin-c) $-\bar{\sigma}_{11}(L / 2,-h / 2)$ for different values of $S-2$ layers $\left(0^{\circ} / 90^{\circ}\right)$.

\begin{tabular}{|c|c|c|c|c|c|c|c|}
\hline \multirow[t]{2}{*}{$S$} & \multicolumn{7}{|c|}{$\bar{\sigma}_{11}(L / 2,-h / 2)$} \\
\hline & Sinzz & Error (\%) & Sin-c & Error (\%) & Sin & Error (\%) & Exact \\
\hline 4 & 31.8 & 6 & 33.5 & 11 & 33.3 & 11 & 30.0 \\
\hline 20 & 703.6 & 0.5 & 703.9 & 0.6 & 692.39 & 1 & 699.7 \\
\hline 40 & 2803.1 & 0.3 & 2805.2 & 0.4 & 2751.7 & 1.4 & 2792.6 \\
\hline
\end{tabular}

are presented in Fig. 6 for the three models. This figure proves again the good performance of the Sinzz model with respect to the two other ones for the thick case. For $S=40$, the results of this family of sine models are very close. Only the results related to the Sinzz model are shown in Fig. 7. Finally, it is seen from these figures that the element performs quite well for thick beams as well as thin beams.

Next, the three layers $\left(0^{\circ} / 90^{\circ} / 0^{\circ}\right)$ case is evaluated. The results are summarized in Tables 5-7. Figs. 8 and 9 show the in-plane and transverse shear stresses and in-plane displacement for $S=4$ and $S=40$. It should be noted that the Sinzz model improves the accuracy of the results only for the thick beam. In fact, the zigzag effect is more pronounced for $S=4$, and the Sinzz model has the best capability to represent this behavior (see Fig. 8). For all cases, the error rate associated to this model remains less than 4.9\%. From Figs. 8 and 9, we can conclude that the results are in good agreement with respect to the reference solution, and the previous remarks about the Sinzz model are validated. For the thin structure, the results of the three models are similar.

\subsubsection{Bending analysis of a sandwich beam under uniform pressure}

The test deals with a sandwich beam under a uniform pressure. The three simple models are assessed in this severe test to evaluate the limitations and the role of the zig-zag function. This example is detailed now.

Geometry: The 3-layer sandwich beam has graphiteepoxy faces and a soft core with thickness $0.1 \mathrm{~h} / 0.8 \mathrm{~h} / 0.1 \mathrm{~h}$ and length-to-thickness ratio $S=2.5, S=5, S=10$; half of the beam is meshed.

Boundary conditions: clamped/clamped $(\mathrm{C} / \mathrm{C})$ beam under an uniform pressure $q_{0}$

Table 2

Comparison between the different Sinus models: without zig-zag effects (Sin), with zig-zag function (Sinzz), and with zig-zag and continuity of the transverse shear stress (Sin-c) $-\bar{u}(0, h / 2)$ and $\bar{w}(L / 2,0)$ for different values of $S-2$ layers $\left(0^{\circ} / 90^{\circ}\right)$.

\begin{tabular}{|c|c|c|c|c|c|c|c|c|c|c|c|c|c|c|}
\hline \multirow[t]{2}{*}{$S$} & \multicolumn{7}{|l|}{$\bar{u}(0, h / 2)$} & \multicolumn{7}{|c|}{$\bar{w}(L / 2,0)$} \\
\hline & Sinzz & Error (\%) & Sin-c & Error (\%) & $\operatorname{Sin}$ & Error (\%) & Exact & Sinzz & Error (\%) & Sin-c & Error (\%) & Sin & Error (\%) & Exact \\
\hline 4 & 4.62 & 1.1 & 3.40 & 25 & 3.93 & 13.6 & 4.56 & 4.5438 & 3 & 4.1811 & 11 & 4.403 & 6.2 & 4.7076 \\
\hline 20 & 486.34 & $<0.01$ & 479.02 & 1 & 482.52 & 0.5 & 486.35 & 2.7036 & 0.2 & 2.6837 & 0.7 & 2.6981 & 0.1 & 2.7092 \\
\hline 40 & 3865.8 & $<0.01$ & 3843.9 & 0.3 & 3858.16 & $<0.1$ & 3865.6 & 2.6450 & $<0.1$ & 2.6350 & 0.2 & 2.6436 & 0.1 & 2.6462 \\
\hline
\end{tabular}



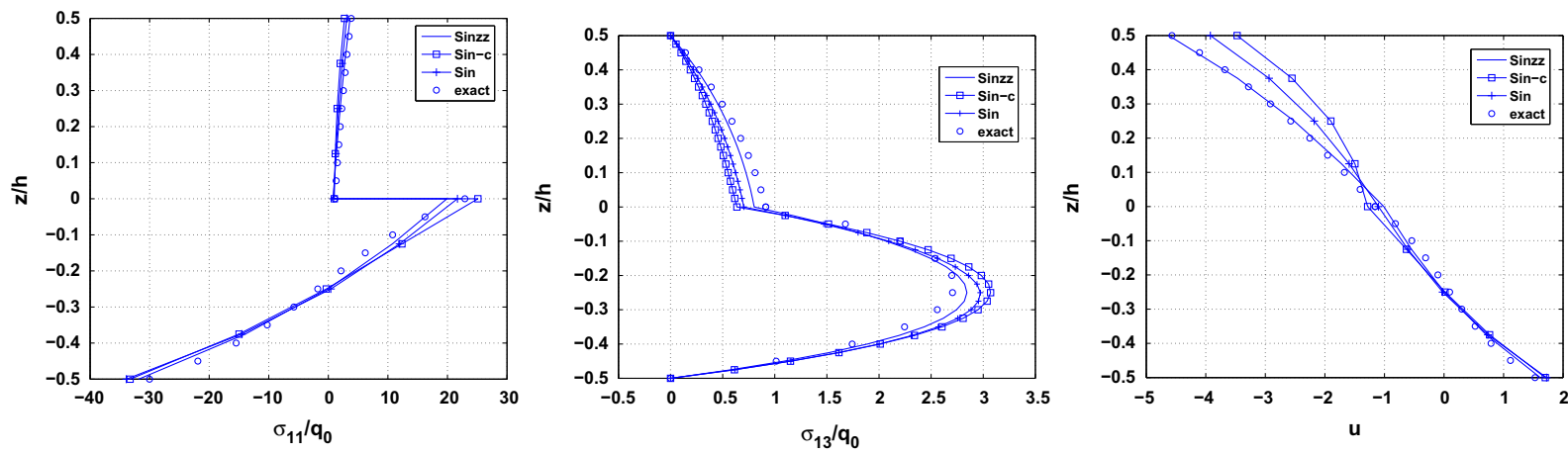

Fig. 6. Distribution of $\bar{\sigma}_{11}$ (left), $\bar{\sigma}_{13}$ (middle) and $\bar{u}$ (right) along the thickness $-S=4-$ two layers $\left(0^{\circ} / 90^{\circ}\right)-\operatorname{Sinzz} / \operatorname{Sin}-\mathrm{c} / \sin$.
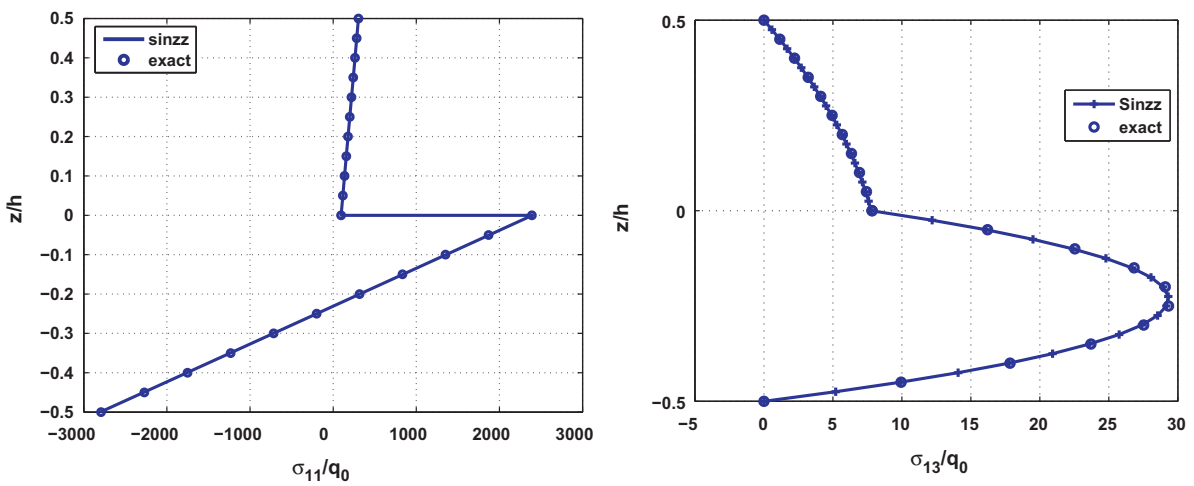

Fig. 7. Distribution of $\bar{\sigma}_{11}$ (left) and $\bar{\sigma}_{13}$ (right) along the thickness $-S=40-$ two layers $\left(0^{\circ} / 90^{\circ}\right)-\operatorname{Sinzz}$.

Table 5

Comparison between the different Sinus models: without zig-zag effects (Sin), with zig-zag function (Sinzz), and with zig-zag and continuity of the transverse shear stress (Sin-c) $-\bar{w}(L / 2,0)$ and $\bar{u}(0, h / 2)$ for different values of $S-3$ layers $\left(0^{\circ} / 90^{\circ} / 0^{\circ}\right)$.

\begin{tabular}{|c|c|c|c|c|c|c|c|c|c|c|c|c|c|c|}
\hline \multirow[b]{2}{*}{$S$} & \multicolumn{7}{|l|}{$\bar{u}(0, h / 2)$} & \multicolumn{7}{|c|}{$\bar{w}(L / 2,0)$} \\
\hline & Sinzz & Error (\%) & Sin-c & Error (\%) & Sin & Error (\%) & Exact & Sinzz & Error (\%) & Sin-c & Error (\%) & Sin & Error (\%) & Exact \\
\hline 4 & 0.9929 & 4.9 & 1.0114 & 7 & 0.8914 & 5 & 0.9456 & 2.8027 & 3 & 2.7894 & 3 & 2.7258 & 5.5 & 2.8899 \\
\hline 20 & 67.368 & 0.6 & 66.992 & $<0.1$ & 66.202 & 1 & 66.941 & 0.6151 & 0.5 & 0.6173 & $<0.01$ & 0.6046 & 2 & 0.6185 \\
\hline 40 & 520.04 & 0.1 & 518.28 & $<0.1$ & 517.64 & $<0.1$ & 519.11 & 0.5371 & 0.1 & 0.5367 & $<0.01$ & 0.5344 & 0.4 & 0.5379 \\
\hline
\end{tabular}

Table 6

Comparison between the different Sinus models: without zig-zag effects (Sin), with zig-zag function (Sinzz), and with zig-zag and continuity of the transverse shear stress $(\operatorname{Sin}-\mathrm{c})-\bar{\sigma}_{13}(0,0)$ for different values of $S-3$ layers $\left(0^{\circ} / 90^{\circ} / 0^{\circ}\right)$

\begin{tabular}{rrlrlccc}
\hline \multirow{3}{*}{$S$} & \multicolumn{1}{c}{$\bar{\sigma}_{13}(0,0)$} & & & & & & \\
\cline { 2 - 7 } & Sinzz & $\begin{array}{l}\text { Error } \\
(\%)\end{array}$ & Sin-c & $\begin{array}{l}\text { Error } \\
(\%)\end{array}$ & Sin & $\begin{array}{l}\text { Error } \\
(\%)\end{array}$ & Exact \\
\hline 4 & 1.4202 & 0.8 & 1.321 & 7 & 1.5207 & 6 & 1.4318 \\
20 & 8.6988 & 0.5 & 8.691 & 0.6 & 8.743 & $<0.1$ & 8.7483 \\
40 & 17.5400 & 0.5 & 17.536 & 0.6 & 17.563 & 0.4 & 17.641 \\
\hline
\end{tabular}

Material properties: Face : $E_{11}=131.1 \mathrm{GPa}, E_{22}=E_{33}=6.9 \mathrm{GPa}$, $G_{12}=3.588 \mathrm{GPa}$,

$G_{13}=3.088 \mathrm{GPa}, G_{23}=2.3322 \mathrm{GPa}$,

$v_{12}=v_{13}=0.32, v_{23}=0.49$.

Core : $E_{11}=0.2208 \mathrm{MPa}, E_{22}=0.2001 \mathrm{MPa}$, $E_{33}=2760 \mathrm{MPa}$

$G_{12}=16.56 \mathrm{MPa}, G_{13}=545.1 \mathrm{MPa}$,

$G_{23}=455.4 \mathrm{MPa}, v_{12}=0.99, v_{13}=0.00003$, $v_{23}=0.00003$

Mesh: $N=16$
Table 7

Comparison between the different Sinus models: without zig-zag effects (Sin), with zig-zag function (Sinzz), and with zig-zag and continuity of the transverse shear stress $\left(\right.$ Sin-c) $-\bar{\sigma}_{11}(L / 2, h / 2)$ for different values of $S-3$ layers $\left(0^{\circ} / 90^{\circ} / 0^{\circ}\right)$.

\begin{tabular}{|c|c|c|c|c|c|c|c|}
\hline \multirow[t]{2}{*}{$S$} & \multicolumn{7}{|c|}{$\bar{\sigma}_{11}(L / 2, h / 2)$} \\
\hline & Sinzz & Error (\%) & Sin-c & Error (\%) & Sin & Error (\%) & Exact \\
\hline 4 & 19.5 & 3.9 & 19.9 & 5 & 19.7 & 5 & 18.8 \\
\hline 20 & 265.4 & 0.8 & 264.6 & 0.5 & 262.0 & 0.5 & 263.2 \\
\hline 40 & 1024.4 & 0.4 & 1023.5 & 0.4 & 1013.6 & 0.6 & 1019.7 \\
\hline
\end{tabular}

Results: the results are presented under a non-dimensional form as: $\quad \bar{w}=100 w Y_{0} / h S^{4} q_{0}, \bar{\sigma}_{11}=\sigma_{11} / S^{2} q_{0}, \bar{\tau}_{13}=\tau_{13} / S q_{0}$ with $Y_{0}=6.9 \mathrm{GPa}$. They are compared with results from a commercial code with a very refined mesh including 3800 dofs (Cf. [69]). It is to be noted that the tranverse shear stress is calculated at $x=L / 8$ because the $2 \mathrm{D} \mathrm{FE}$ solution is not valid at a fixed edge.

Table 8 shows that the Sinzz model allows us to improve the quality of the estimation of the in-plane, transverse shear stresses 

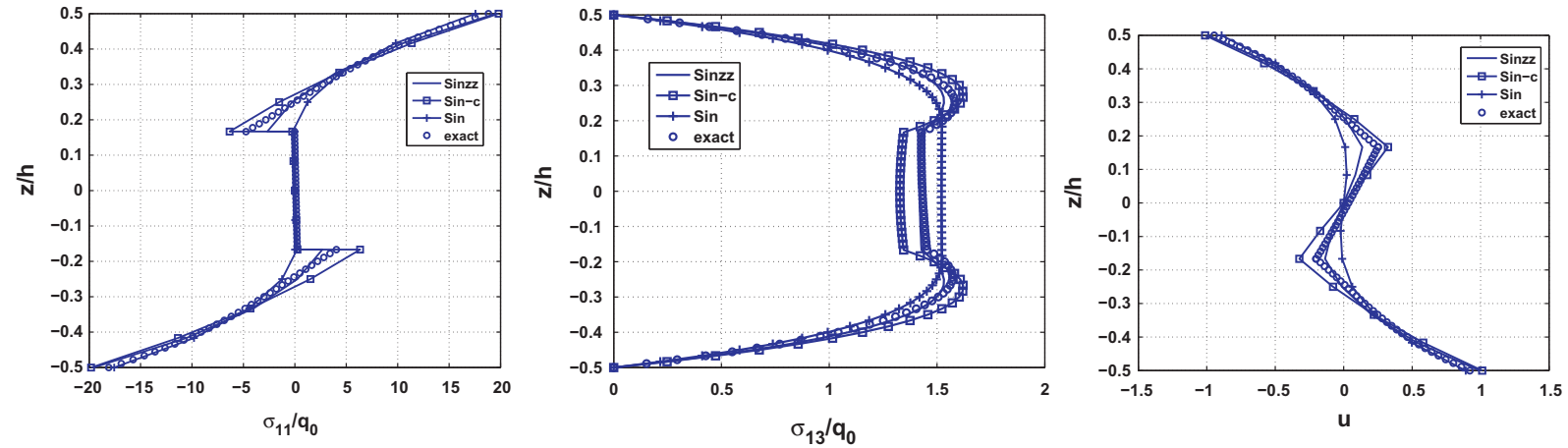

Fig. 8. Distribution of $\bar{\sigma}_{11}$ (left) $-\bar{\sigma}_{13}$ (middle)- $\bar{u}$ (right) along the thickness $-S=4-$ three layers $\left(0^{\circ} / 90^{\circ} / 0^{\circ}\right)-\operatorname{Sinzz} / \operatorname{Sin}-\mathrm{c} / \sin$.
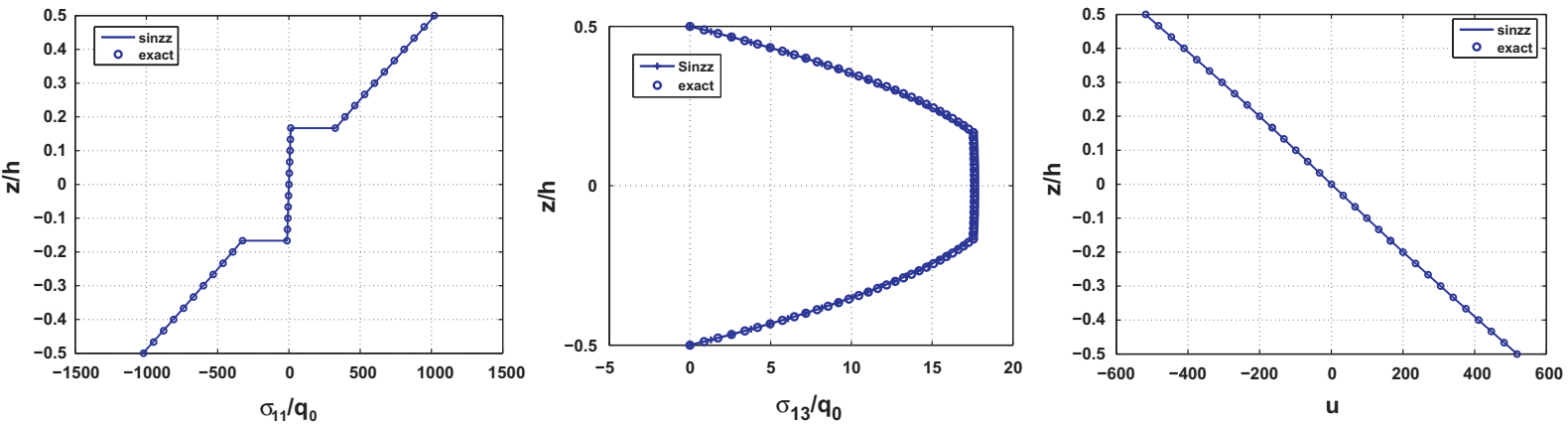

Fig. 9. Distribution of $\bar{\sigma}_{11}$ (left) and $\bar{\sigma}_{13}$ (middle) $-\bar{u}$ (right) along the thickness $-S=40$ - three layers $\left(0^{\circ} / 90^{\circ} / 0^{\circ}\right)-\operatorname{Sinzz}$.

Table 8

Comparison between the different Sinus models: without zig-zag effects (Sin), with zig-zag function (Sinzz), and with zig-zag and continuity of the transverse shear stress (Sin-c) - sandwich - uniform pressure - clamped/clamped.

\begin{tabular}{|c|c|c|c|c|c|c|c|c|}
\hline$S$ & & Sinzz & Error (\%) & Sin-c & Error (\%) & $\operatorname{Sin}$ & Error (\%) & ANSYS \\
\hline \multirow[t]{3}{*}{2.5} & $\bar{\sigma}_{13}(L / 8,0)$ & 0.3261 & 0.1 & 0.3089 & 5.3 & 0.3306 & 1 & 0.3263 \\
\hline & $\bar{\sigma}_{11}(L / 2,-h / 2)$ & 2.0642 & 1 & 2.2184 & 5 & 1.9416 & 7 & 2.1000 \\
\hline & $\bar{w}(L / 2,0)$ & 19.1094 & 6 & 17.9749 & 12 & 17.8530 & 13 & 20.5340 \\
\hline \multirow[t]{3}{*}{5} & $\bar{\sigma}_{13}(L / 8,0)$ & 0.3795 & 2 & 0.3844 & 0.9 & 0.3912 & 0.8 & 0.3880 \\
\hline & $\bar{\sigma}_{11}(L / 2,-h / 2)$ & 0.9295 & 1 & 0.9459 & 0.7 & 0.8717 & 7 & 0.9398 \\
\hline & $\bar{w}(L / 2,0)$ & 5.5730 & 6 & 5.6569 & 5.0 & 5.3975 & 9 & 5.9550 \\
\hline \multirow[t]{3}{*}{10} & $\bar{\sigma}_{13}(L / 8,0)$ & 0.3965 & 4 & 0.3973 & 3.7 & 0.3976 & 4 & 0.4125 \\
\hline & $\bar{\sigma}_{11}(L / 2,-h / 2)$ & 0.6175 & 0.3 & 0.6215 & 0.4 & 0.6029 & 2 & 0.6193 \\
\hline & $\bar{w}(L / 2,0)$ & 1.7153 & 6 & 1.7810 & 3 & 1.6868 & 8 & 1.8358 \\
\hline
\end{tabular}
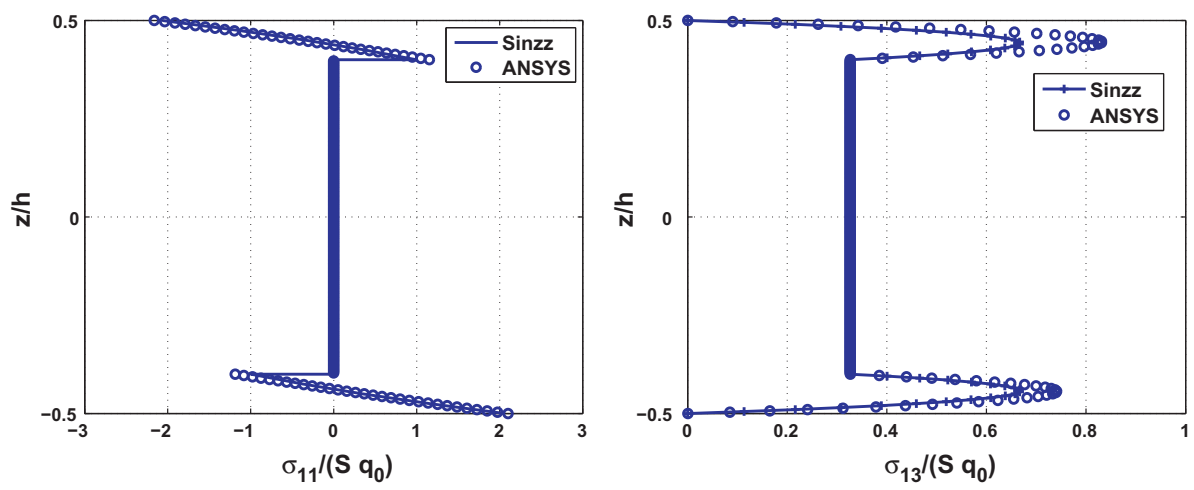

Fig. 10. Distribution of $\bar{\sigma}_{11}$ and $\bar{\sigma}_{13}$ along the thickness $-S=2.5-$ sandwich - Sinzz - uniform pressure $-\mathrm{C} / \mathrm{C}$.

and the deflection for the very thick cases. The inclusion of the zigzag function is not sufficient for the moderately thick structures, and the conditions on the continuity of the transverse shear stress become also important. Figs. 10 and 11 show that the distribution of the in-plane stress is rather good. Nevertheless, these models cannot take into account the non-symmetrical distribution of the 

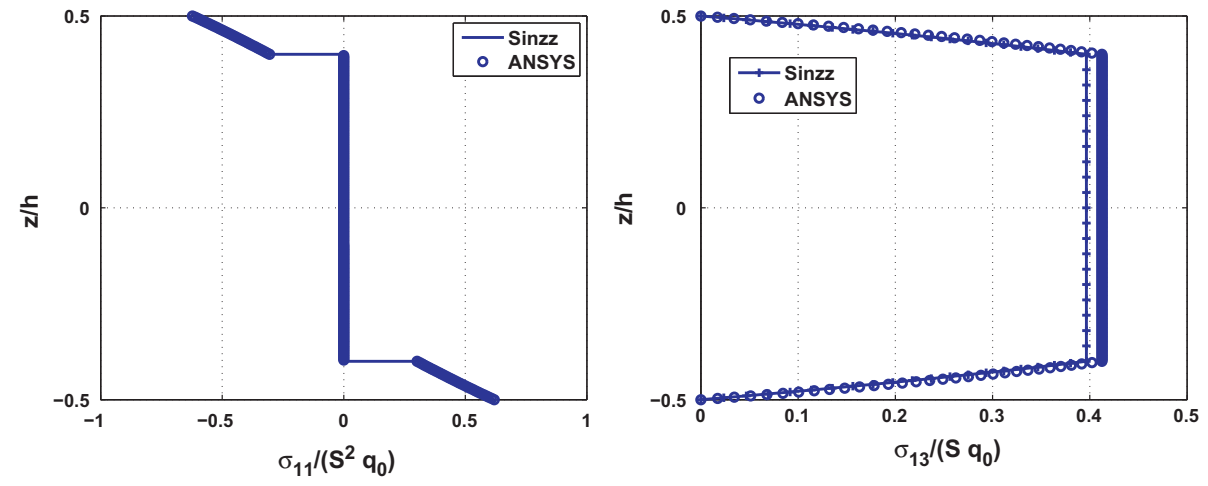

Fig. 11. Distribution of $\bar{\sigma}_{11}$ and $\bar{\sigma}_{13}$ along the thickness $-S=10-$ sandwich - Sinzz - uniform pressure $-\mathrm{C} / \mathrm{C}$.

Table 9

Comparison between the different Sinus models: without zig-zag effects (Sin), with zig-zag function (Sinzz), and with zig-zag and continuity of the transverse shear stress (Sin-c) - error rate for the in-plane and transverse displacements.

\begin{tabular}{|c|c|c|c|c|c|c|c|c|c|c|}
\hline \multirow[b]{2}{*}{$S$} & \multicolumn{5}{|l|}{$\bar{u}$} & \multicolumn{5}{|l|}{$\bar{w}$} \\
\hline & 4 & 10 & 20 & 40 & 100 & 4 & 10 & 20 & 40 & 100 \\
\hline \multicolumn{11}{|l|}{$\eta=10$} \\
\hline Reference & 26.62 & 389.01 & 3078.81 & 24564.1 & 383518 & 42.28 & 27.29 & 25.13 & 24.59 & 24.44 \\
\hline $\operatorname{Sin}$ & $1.7 \%$ & $0.4 \%$ & $0.2 \%$ & $0.1 \%$ & $0.1 \%$ & $4 \%$ & $1.5 \%$ & $0.7 \%$ & $0.5 \%$ & $0.5 \%$ \\
\hline Sin-c & $0.5 \%$ & $0.2 \%$ & $0.04 \%$ & $0.01 \%$ & $0.002 \%$ & $1 \%$ & $0.2 \%$ & $0.04 \%$ & $0.01 \%$ & $0.003 \%$ \\
\hline Sinzz & $0.2 \%$ & $0.2 \%$ & $0.1 \%$ & $0.1 \%$ & $0.1 \%$ & $2 \%$ & $0.9 \%$ & $0.6 \%$ & $0.5 \%$ & $0.5 \%$ \\
\hline \multicolumn{11}{|l|}{$\eta=100$} \\
\hline Reference & 43.61 & 463.74 & 3444.01 & 27014 & 419741 & 198.49 & 55.01 & 33.80 & 28.47 & 26.97 \\
\hline $\operatorname{Sin}$ & $24 \%$ & $6 \%$ & $1.7 \%$ & $0.5 \%$ & $0.1 \%$ & $48 \%$ & $29 \%$ & $12 \%$ & $4 \%$ & $1 \%$ \\
\hline Sin-c & $0.3 \%$ & $0.2 \%$ & $0.07 \%$ & $0.02 \%$ & $0.00 \%$ & $0.8 \%$ & $0.1 \%$ & $0.04 \%$ & $0.00 \%$ & $0.00 \%$ \\
\hline Sinzz & $7 \%$ & $2 \%$ & $0.7 \%$ & $0.2 \%$ & $0.1 \%$ & $23 \%$ & $14 \%$ & $6 \%$ & $2 \%$ & $0.7 \%$ \\
\hline
\end{tabular}

Table 10

Comparison between the different Sinus models: without zig-zag effects (Sin), with zig-zag function (Sinzz), and with zig-zag and continuity of the transverse shear stress (Sin-c) - error rate for the in-plane normal and transverse shear stresses.

\begin{tabular}{|c|c|c|c|c|c|c|c|c|c|c|}
\hline & \multicolumn{5}{|l|}{$\bar{\sigma}_{11}$} & \multicolumn{5}{|l|}{$\bar{\sigma}_{13}$} \\
\hline & 4 & 10 & 20 & 40 & 100 & 4 & 10 & 20 & 40 & 100 \\
\hline \multicolumn{11}{|l|}{$\eta=10$} \\
\hline Reference & -19.57 & -114.38 & -452.63 & -1805.6 & -11353 & 1.49 & 3.75 & 7.50 & 15.02 & 37.53 \\
\hline Sin & $2 \%$ & $0.7 \%$ & $0.5 \%$ & $0.4 \%$ & $1 \%$ & $1.1 \%$ & $0.3 \%$ & $0.2 \%$ & $0.1 \%$ & $0.1 \%$ \\
\hline Sin-c & $0.4 \%$ & $0.1 \%$ & $0.04 \%$ & $0.07 \%$ & $0.6 \%$ & $0.7 \%$ & $0.2 \%$ & $0.1 \%$ & $0.1 \%$ & $0.1 \%$ \\
\hline Sinzz & $0.5 \%$ & $0.5 \%$ & $0.4 \%$ & $0.4 \%$ & $1 \%$ & $1.3 \%$ & $0.3 \%$ & $0.2 \%$ & $0.1 \%$ & $0.1 \%$ \\
\hline \multicolumn{11}{|l|}{$\eta=100$} \\
\hline Reference & -32.06 & -136.35 & -506.30 & -1985.7 & -12451 & 1.38 & 3.53 & 7.08 & 14.18 & 35.47 \\
\hline Sin & $24 \%$ & $6 \%$ & $2 \%$ & $0.8 \%$ & $1 \%$ & $1 \%$ & $0.0 \%$ & $0.1 \%$ & $0.1 \%$ & $0.1 \%$ \\
\hline Sin-c & $0.4 \%$ & $0.1 \%$ & $0.00 \%$ & $0.06 \%$ & $0.8 \%$ & $0.7 \%$ & $0.2 \%$ & $0.1 \%$ & $0.1 \%$ & $0.1 \%$ \\
\hline Sinzz & $8 \%$ & $2 \%$ & $1 \%$ & $0.5 \%$ & $1 \%$ & $0.6 \%$ & $0.2 \%$ & $0.1 \%$ & $0.1 \%$ & $0.1 \%$ \\
\hline
\end{tabular}

quantity of interest for the very thick cases (see Fig. 10 right for instance).

\subsubsection{Bending analysis of a sandwich beam under a sinusoidal pressure}

The test deals with a sandwich beam under sinusoidal pressure with different values of face to core stiffness ratio. The three simple models are assessed in this severe test to evaluate the limitations and the role of the zig-zag function. This case has already been studied in [50].

This example is detailed now.

geometry: The 3-layer sandwich beam has aluminum alloy faces and a soft core with thickness $0.1 \mathrm{~h} / 0.8 \mathrm{~h} / 0.1 \mathrm{~h}$ and length-to-thickness ratio $S=4 / 10 / 20 / 40 / 100$; half of the beam is meshed.
Boundary conditions: simply supported $(\mathrm{S} / \mathrm{S})$ beam under a sinusoidal pressure $q\left(x_{1}\right)=q_{0} \sin \left(\frac{\pi x_{1}}{L}\right)$

Material properties: Face : $E_{f}=73000 \mathrm{MPa}, v=0.34$.

\section{Mesh: $N=16$}

Core : $E_{c}=\eta E_{f}$, with $\eta=10,100$

Results: The results $\left(\bar{u}, \bar{w}, \bar{\sigma}_{11}, \bar{\sigma}_{13}\right)$ are made non-dimensional using:

$$
\begin{gathered}
\bar{u}=\frac{E_{f} u_{1}(0,-h / 2)}{h q_{0}} \bar{w}=\frac{100 E_{f} u_{3}(L / 2,0)}{S^{4} h q_{0}} \\
\bar{\sigma}_{11}=\frac{\sigma_{11}(L / 2,-h / 2)}{q_{0}} \bar{\sigma}_{13}=\frac{\sigma_{13}(0,0)}{q_{0}}
\end{gathered}
$$

They are provided in Table 9 and Table 10. They are compared with results from a commercial code with a very refined mesh including 3800 dofs. 
The following remarks can be made:

- For $\eta=10$, the maximum error rate of the Sinzz model is $2 \%$ (for $S=4$ ). In this case, the use of the Sinzz model is justified only for the thick beam when compared with the Sin model.

- When $\eta$ increases, the role of the additional zig-zag function is significant when compared with the Sin model, even for the moderately thick structures. The accuracy of results decreases quickly when the length-to-thickness ratio decreases (thick beam). In this case, the validity of the Sinzz model is limited to the moderately thick or thin beam.

- For the thin structure $S \geqslant 40$, the error rate for the Sinzz model remains less than $2 \%$.

- For this sandwich case, the Sin-c model is the most accurate model regardless of the degree of anisotropy and the slenderness ratio. So, it shows that the capability to take into account both the continuity conditions on the transverse shear stress and the zig-zag effect is an important feature in the framework of the family of sinus models.

Note that the error of the transverse displacement is more sensitive to the variation of the degree of anisotropy $\eta$. For the thick cases, it is necessary to enrich this term to avoid this and include the transverse normal strain.

\subsection{Free-vibration tests}

In this section, some examples of sandwich and laminated beams are used to evaluate this finite element in the free vibration case. It concerns a wide range of length-to-thickness ratios for symmetric, unsymmetric and sandwich beams. These examples are taken from [70-72]. The results are compared with the ANSYS solution with a very refined mesh or the exact 2D solution. Some of these examples are extended to a very thick beam to assess this finite element.

\subsubsection{Free vibration of symmetric laminated composite [70,71]}

The example is issued from [70] and [71]. It deals with a symmetric laminated composite with the following characteristics:

Geometry: The beam studied has a length of $L=6.35$ $\mathrm{m}$, and a thickness $h=0.2794 \mathrm{~m}$ (thin $S \approx 22.7$ ), and $h=2.794 \mathrm{~m}$ (thick $S \approx 2.2$ ). It possesses three layers at $\left(90^{\circ} / 0^{\circ} / 90^{\circ}\right)$, with thickness $(0.25 \mathrm{~h} / 0.5 \mathrm{~h} / 0.25 \mathrm{~h})$.

Boundary conditions: simply supported beam

Material properties: The material used is boron epoxy which has the following mechanical properties: $E_{11}=241.5 \mathrm{GPa}, E_{22}=E_{33}=18.89 \mathrm{GPa}, G_{12}=$ $G_{13}=5.18 \mathrm{GPa}$

$G_{23}=3.45 \mathrm{GPa}, v_{12}=v_{13}=0.24$, $v_{23}=0.25, \rho=2015 \mathrm{~kg} / \mathrm{m}^{3}$.

Mesh: $N=8$

Results: The mode shapes are precised as: bend, sh, $t / c$ for bending, shear, axial and traction/compression mode respectively.

(Tables 11 and 12 present numerical values of frequencies for the thin and very thick beam. Results of the Sinzz model are better than those of the Sin and Sin-c models regardless of the length-tothickness ratio. For the thin structure, the results of Table 11 show the good agreement with reference values for eight natural frequencies. The maximal error rate does not exceed 2.4 for all models. For the very thick structure, we can highlight the importance of the zig-zag function for the three highest frequencies.
Table 11

Comparison between the different Sinus models: without zig-zag effects (Sin), with zig-zag function (Sinzz), and with zig-zag and continuity of the transverse shear stress $\left(\right.$ Sin-c) - natural frequencies - 3 layers $\left(90^{\circ} / 0^{\circ} / 90^{\circ}\right)-S \approx 22.7$.

\begin{tabular}{|c|c|c|c|c|c|c|c|}
\hline & $\operatorname{Sinzz}$ & $\begin{array}{l}\text { Error } \\
(\%)\end{array}$ & Sin-c & $\begin{array}{l}\text { Error } \\
(\%)\end{array}$ & Sin & $\begin{array}{l}\text { Error } \\
(\%)\end{array}$ & Ansys \\
\hline \multicolumn{8}{|c|}{ Freq $(\mathrm{Hz})$ thin beam } \\
\hline Bend & 14.94 & 0.0 & 14.98 & 0.3 & 14.97 & 0.2 & 14.93 \\
\hline Bend & 57.68 & 0.0 & 57.94 & 0.4 & 57.85 & 0.3 & 57.67 \\
\hline Bend & 123.13 & 0.1 & 123.96 & 0.8 & 123.55 & 0.5 & 122.90 \\
\hline Bend & 205.35 & 0.4 & 207.23 & 1.3 & 206.18 & 0.8 & 204.50 \\
\hline Bend & 299.38 & 0.7 & 302.75 & 1.8 & 300.71 & 0.9 & 297.23 \\
\hline Bend & 401.17 & 0.9 & 406.91 & 2.4 & 403.60 & 1.5 & 397.28 \\
\hline Bend & 510.46 & 1.6 & 517.43 & 3 & 512.67 & 2 & 502.19 \\
\hline sh & 632.94 & 0.4 & 632.94 & 0.4 & 640.06 & 1.5 & 630.25 \\
\hline
\end{tabular}

Table 12

Comparison between the different Sinus models: without zig-zag effects (Sin), with zig-zag function (Sinzz), and with zig-zag and continuity of the transverse shear stress $\left(\right.$ Sin-c) - natural frequencies -3 layers $\left(90^{\circ} / 0^{\circ} / 90^{\circ}\right)-S \approx 2.2$.

\begin{tabular}{|c|c|c|c|c|c|c|c|}
\hline & Sinzz & $\begin{array}{l}\text { Error } \\
(\%)\end{array}$ & Sin-c & $\begin{array}{l}\text { Error } \\
(\%)\end{array}$ & $\operatorname{Sin}$ & $\begin{array}{l}\text { Error } \\
(\%)\end{array}$ & Ansys \\
\hline \multicolumn{8}{|c|}{ Freq $(\mathrm{Hz})$ thick beam } \\
\hline Bend & 82.62 & 0.5 & 83.66 & 1 & 82.81 & 0.7 & 82.17 \\
\hline Bend & 195.18 & 0.0 & 195.67 & 0.3 & 195.62 & 0.2 & 195.22 \\
\hline sh & 274.98 & 0.2 & 274.94 & 0.2 & 277.98 & 1.3 & 274.31 \\
\hline Bend & 311.31 & 0.4 & 313.36 & 1 & 319.36 & 2.9 & 310.07 \\
\hline Bend & 429.81 & 1.3 & 442.07 & 4.1 & 460.18 & 8.4 & 424.311 \\
\hline Bend & 460.54 & 5.0 & 501.47 & 14.2 & 515.41 & 17.4 & 438.81 \\
\hline Bend & 550.61 & 2.5 & 585.51 & 8.9 & 621.47 & 15.6 & 537.42 \\
\hline
\end{tabular}

3.2.2. free vibration of anti-symmetric lay-up

In this section, a laminated composite with an anti-symmetric lay-up is considered.

Geometry: composite cross-ply beam $\left(0^{\circ} / 90^{\circ}\right)$ and length-to-thickness ratio $S=2, \quad S=5$, $S=10, S=20$.

Boundary conditions: free vibration of a simply supported beam Material properties:

$$
\begin{aligned}
& E_{L}=181 \mathrm{GPa}, E_{T}=10.3 \mathrm{GPa}, G_{L T}=7.17 \mathrm{GPa}, \\
& G_{T T}=2.87 \mathrm{GPa}, v_{L T}=0.25, v_{T T}=0.33
\end{aligned}
$$

where $L$ and $T$ refer to the fiber and transverse direction respectively.

Results: the results are presented under a non-dimensional natural frequency as follows: $\bar{\omega}=\omega L S\left(\rho / Y_{0}\right)^{1 / 2}$, with $Y_{0}=10.3 \mathrm{GPa}, \rho=1578 \mathrm{~kg} / \mathrm{m}^{3}$ (see Table 13 ). They are compared with two-dimensional results computed from ANSYS with a refined mesh [73]. The thickness modes are omitted because the present models have not the capability to predict them due to the constant approximation across the thickness of $u_{3}$.

For the very thick beam $(S=2 / 5)$, it is necessary to include the zig-zag function in the Sin model. The improvement is really significant compared with the two other models. In this case, these ones give very poor results.

When $S$ is greater than 10 , the error rate of the Sinzz model remains less than $3.6 \%$. The influence of the additional function occurs mainly for the highest bending modes.

\subsection{3. free vibration of sandwich beam [72]}

The example of sandwich beam has the following characteristics: 
Table 13

Comparison between the different Sinus models: without zig-zag effects (Sin), with zig-zag function (Sinzz), and with zig-zag and continuity of the transverse shear stress (Sin-c) - natural frequencies - anti-symmetric lay-up $\left(0^{\circ} / 90^{\circ}\right)$.

\begin{tabular}{|c|c|c|c|c|c|c|c|c|}
\hline \multirow[t]{2}{*}{$S$} & \multicolumn{8}{|c|}{ Natural frequencies $\bar{\omega}$} \\
\hline & & Sinzz & Error (\%) & Sin-c & Error (\%) & Sin & Error (\%) & Ansys \\
\hline \multirow[t]{5}{*}{2} & Bend & 3.31 & 3.5 & 3.51 & 10 & 3.38 & 6 & 3.20 \\
\hline & Bend & 7.93 & 7.6 & 9.38 & 27 & 8.63 & 17 & 7.37 \\
\hline & sh & 8.19 & 5.6 & 8.04 & 4 & 8.77 & 13 & 7.76 \\
\hline & Bend & 9.11 & 3.0 & 16.34 & 85 & 14.80 & 67 & 8.85 \\
\hline & Bend & 13.65 & 24 & 23.79 & 117 & 22.07 & 101 & 10.94 \\
\hline \multirow[t]{6}{*}{5} & Bend & 4.81 & 0.8 & 4.87 & 2 & 4.83 & 1 & 4.77 \\
\hline & Bend & 14.97 & 2.4 & 15.60 & 6 & 15.19 & 4 & 14.61 \\
\hline & Bend & 26.56 & 4.5 & 28.64 & 12 & 27.30 & 7 & 25.40 \\
\hline & tc & 35.99 & 1.6 & 36.39 & 3 & 38.12 & 7 & 35.42 \\
\hline & Bend & 38.70 & 7.4 & 43.09 & 19 & 40.29 & 12 & 36.02 \\
\hline & sh & 49.69 & 2.4 & 50.29 & 3 & 54.15 & 11 & 48.52 \\
\hline \multirow[t]{6}{*}{10} & Bend & 5.30 & 0.2 & 5.32 & 0.5 & 5.30 & 0.3 & 5.29 \\
\hline & Bend & 19.26 & 0.7 & 19.49 & 2 & 19.33 & 1 & 19.12 \\
\hline & Bend & 38.33 & 1.5 & 39.33 & 4 & 38.67 & 2 & 37.77 \\
\hline & Bend & 60.01 & 2.4 & 62.57 & 7 & 60.91 & 4 & 58.60 \\
\hline & Bend & 83.08 & 3.6 & 88.13 & 9 & 84.87 & 6 & 80.22 \\
\hline & tc & 88.85 & 0.5 & 88.92 & 0.5 & 90.06 & 2 & 88.44 \\
\hline \multirow[t]{7}{*}{20} & Bend & 5.45 & 0.0 & 5.46 & 0.1 & 5.45 & $<0.1$ & 5.45 \\
\hline & Bend & 21.22 & 0.2 & 21.28 & 0.4 & 21.23 & 0.3 & 21.18 \\
\hline & Bend & 45.76 & 0.5 & 46.08 & 1 & 45.86 & 0.7 & 45.55 \\
\hline & Bend & 77.28 & 0.9 & 78.23 & 2 & 77.58 & 1 & 76.59 \\
\hline & Bend & 114.14 & 1.5 & 116.31 & 3 & 114.86 & 2 & 112.40 \\
\hline & Bend & 155.18 & 2.4 & 159.32 & 5 & 156.58 & 3 & 151.48 \\
\hline & tc & 188.09 & 0.1 & 188.09 & 0.1 & 188.63 & 0.4 & 187.89 \\
\hline
\end{tabular}

Table 14

Comparison between the different Sinus models: without zig-zag effects (Sin), with zig-zag function (Sinzz), and with zig-zag and continuity of the transverse shear stress (Sin-c) - natural frequencies - sandwich beam.

\begin{tabular}{|c|c|c|c|c|c|c|c|c|c|}
\hline \multirow[t]{2}{*}{$S$} & \multicolumn{8}{|c|}{ Natural frequencies $\bar{\omega}$} & \multirow[b]{2}{*}{ Exact 2D [72] } \\
\hline & & Sinzz & Error (\%) & Sin-c & Error (\%) & $\operatorname{Sin}$ & Error (\%) & Ansys & \\
\hline \multirow[t]{5}{*}{2} & Bend & 3.68 & 4.2 & 3.57 & 1.3 & 3.67 & 4 & 3.53 & - \\
\hline & sh & 5.50 & 3.0 & 5.34 & 0.0 & 5.54 & 3.7 & 5.34 & - \\
\hline & Bend & 8.00 & 5.5 & 8.03 & 5.9 & 7.99 & 5.4 & 7.58 & - \\
\hline & Bend & 12.84 & 7.0 & 13.77 & 14 & 13.22 & 10 & 11.99 & - \\
\hline & Bend & 17.96 & 8.6 & 21.08 & 27 & 19.61 & 18 & 16.53 & - \\
\hline \multirow[t]{5}{*}{5} & Bend & 8.07 & 3.1 & 7.85 & 0.3 & 8.09 & 3.4 & 7.82 & 7.82 \\
\hline & Bend & 17.96 & 3.9 & 17.43 & 0.8 & 17.96 & 3.9 & 17.28 & 17.27 \\
\hline & Bend & 28.11 & 4.4 & 27.42 & 1.8 & 28.01 & 4. & 26.93 & 26.90 \\
\hline & sh & 34.40 & 3 & 33.42 & 0. & 34.66 & 3.7 & 33.40 & - \\
\hline & Bend & 38.81 & 4.9 & 38.27 & 3.4 & 38.62 & 4.3 & 37.01 & 36.93 \\
\hline \multirow[t]{7}{*}{10} & Bend & 12.46 & 1.8 & 12.25 & 0.1 & 12.49 & 2.1 & 12.23 & 12.23 \\
\hline & Bend & 32.27 & 3.1 & 31.41 & 0.3 & 32.37 & 3.4 & 31.30 & 31.29 \\
\hline & Bend & 52.07 & 3.6 & 50.53 & 0.5 & 52.17 & 3.8 & 50.26 & 50.21 \\
\hline & Bend & 71.88 & 3.9 & 69.77 & 0.8 & 71.90 & 3.8 & 69.21 & 68.09 \\
\hline & Bend & 92.05 & 4.1 & 89.52 & 1.2 & 91.88 & 3.9 & 88.41 & 88.18 \\
\hline & Bend & 112.83 & 4.4 & 110.11 & 1.9 & 112.43 & 4. & 108.02 & 107.61 \\
\hline & $t / c$ & 121.04 & 0.8 & 121.04 & 0.8 & 121.04 & 0.8 & 120.03 & - \\
\hline \multirow[t]{6}{*}{20} & Bend & 15.44 & 0.4 & 15.39 & 0. & 15.50 & 0.8 & 15.38 & 15.38 \\
\hline & Bend & 49.87 & 1.8 & 49.04 & 0.1 & 49.99 & 2. & 48.98 & 48.94 \\
\hline & Bend & 89.25 & 2.6 & 87.18 & 0.2 & 89.53 & 2.8 & 87.01 & 86.90 \\
\hline & Bend & 169.10 & 3.4 & 164.26 & 0.4 & 169.56 & 3.6 & 163.58 & 163.12 \\
\hline & Bend & 209.04 & 3.7 & 202.88 & 0.6 & 209.45 & 3.8 & 201.64 & 200.87 \\
\hline & $\mathrm{t} / \mathrm{c}$ & 242.08 & 0.2 & 242.06 & 0.2 & 242.08 & 0.2 & 241.61 & - \\
\hline
\end{tabular}

Geometry: The 3-layer sandwich beam has graphiteepoxy faces and a soft core with thickness $0.1 \mathrm{~h} / 0.8 \mathrm{~h} / 0.1 \mathrm{~h}$ and length-to-thickness ratio $S=2, S=5, S=10, S=20$.

Boundary conditions: simply supported beam

Material properties: Face : $E_{11}=131.1 \mathrm{GPa}, E_{22}=E_{33}=6.9 \mathrm{GPa}$, $G_{12}=3.588 \mathrm{GPa}, G_{13}=3.088 \mathrm{GPa}, G_{23}=2.3322$ $\mathrm{GPa}, \quad v_{12}=v_{13}=0.32, \quad v_{23}=0.49, \rho_{f}=1000$ $\mathrm{kg} / \mathrm{m}^{3}$. Core : $E_{11}=0.2208 \mathrm{MPa}, E_{22}=0.2001$ $\mathrm{MPa}, E_{33}=2760 \mathrm{MPa}, G_{12}=16.56 \mathrm{MPa}, G_{13}=$ $545.1 \mathrm{MPa}, \mathrm{G}_{23}=455.4 \mathrm{MPa}, \quad v_{12}=0.99$ $v_{13}=0.00003, v_{23}=0.00003, \rho_{c}=70 \mathrm{~kg} / \mathrm{m}^{3}$.
Results: results are presented under a nondimensional natural frequency as follows: $\bar{\omega}=\omega L S\left(\rho_{f} / Y_{0}\right)^{1 / 2}$ with $Y_{0}=6.9 \mathrm{GPa}-\mathrm{Cf}$. Table 14. We define an anisotropy ratio $\eta_{v}$ such that: $E_{\text {face }}=\eta_{v} E_{\text {core }}$ and $G_{\text {face }}=\eta_{v} G_{\text {core }}$

Table 14 shows that the influence of the zig-zag function is limited to the highest modes for the very thick beam. The most important characteristic is the capability of the model to take into account both the interlaminar continuity and the zig-zag effect. For $S \geqslant 5$, the error rate for the Sin-c model does not exceed $3.4 \%$. 

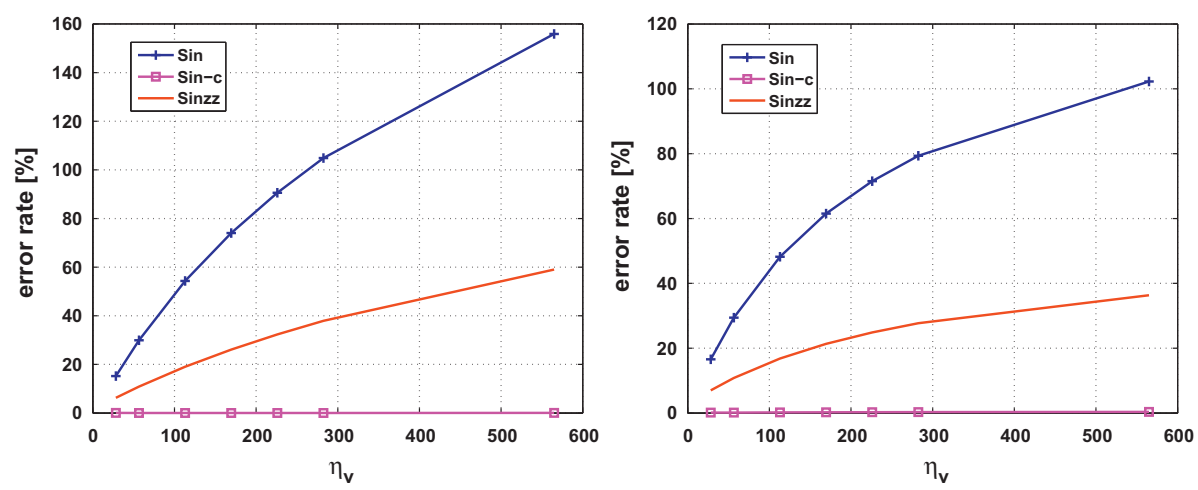

Fig. 12. Error rate for the 1 st (left)/2nd (right) mode with respect to the anisotropy ratio $\eta_{v}-S=10$

To estimate the influence of the degree of anisotropy, the error rate with respect to the anisotropy coefficient $\eta_{v}$ for the first and second modes is presented in Fig. 12. The three models are compared. It can be seen that the additional function allows to decrease the error rate when $\eta_{v}$ increases. But, the previous remark in Section 3.1.4 is confirmed, that is, the Sin-c model which has a double feature (continuity and zig-zag effect) is necessary. The figure shows that this model is insensitive to the anisotropy ratio for the sandwich beam.

\section{Conclusion}

In this article, a sine model including the zig-zag function, denoted Sinzz, has been presented and evaluated through a wide variety of stacking sequences, length-to-thickness ratios in statics and vibration. It consists of a three-node multilayered (sandwich and laminated) beam finite element without numerical pathologies. There is no need for transverse shear correction factors. The number of unknowns is low.

This element is assessed in the framework of the sinus model for heterogeneous beam. Each of one has different features: special attention is pointed towards the influence of this additional function which allows to represent the slope discontinuity of the inplane displacement through the thickness. Only one more unknown is necessary. Another important aspect concerning the continuity conditions of the transverse shear stress is also discussed.

The following comments can be made about the specific role of this zig-zag function with respect to the other FE belonging to the sinus family:

- the improvement of the results is important for the thick beams.

- the influence increases when the degree of anisotropy increases for thick and moderately thick sandwich beams.

Moreover, note that the sine model must not only take into account the zig-zag effect but also the continuity conditions of the transverse shear stress for the sandwich beam. These two requirements are particularly important when the degree of anisotropy increases for static or vibration analysis.

\section{References}

[1] Carrera E. Historical review of zig-zag theories for multilayered plates and shells. Appl Mech Rev 2003;56(3):287-308.

[2] Basset A. On the extension and flexure of cylindrical and spherical thin elastic shells. Philos Trans Roy Soc (Lond) Ser A 1890;181:433-80.

[3] Tanigawa Y, Murakami H, Ootao Y. Transient thermal stress analysis of a laminated composite beam. J Therm Stresses 1989;12:25-39.

[4] Mindlin R. Influence of rotatory inertia and shear on flexural motions of isotropic, elastic plates. J Appl Mech ASME 1951;18:31-8.
[5] Yang P, Norris C, Stavsky Y. Elastic wave propagation in heterogeneous plates. Int J Solids Struct 1966:2:665-84.

[6] Librescu L. On the theory of anisotropic elastic shells and plates. Int J Solids Struct 1967;3:53-68

[7] Whitney J, Sun C. A higher order theory for extensional motion of laminated composites. J Sound Vib 1973;30:85-97.

[8] Lo K, Christensen R, Wu F. A higher-order theory of plate deformation. part ii: Laminated plates. J Appl Mech ASME 1977;44:669-76.

[9] Reddy J. A simple higher-order theory for laminated composite plates. J Appl Mech ASME 1984;51(4):745-52.

[10] Matsunaga H. Assessment of a global higher-order deformation theory for laminated composite and sandwich plates. Compos Struct 2002;56:279-91.

[11] Kant T, Swaminathan K. Analytical solutions for the static analysis of laminated composite and sandwich plates based on a higher order refined theory. Compos Struct 2002;56:329-44.

[12] Swaminathan K, Patil S. Higher order refined computational model with 12 degrees of freedom for the stress analysis of antisymmetric angle-ply plates analytical solutions. Compos Struct 2007;80:595-608.

[13] Rao M, Desai Y. Analytical solutions for vibrations of laminated and sandwich plates using mixed theory. Compos Struct 2004:63:361-73.

[14] Carrera E. A priori vs. a posteriori evaluation of transverse stresses in multilayered orthotropic plates. Compos Struct 2000;48(4):245-60.

[15] Kim J-S, Cho M. Enhanced first-order theory based on mixed formulation and transverse normal effect. Int J Solids Struct 2007;44:1256-76.

[16] Kant T, Gupta A. A finite element model for a high order shear deformable beam theory. J Sound Vib 1988;125:193-202.

[17] Subramanian P. Flexural analysis of symmetric laminated composite beams using $c^{1}$ finite element. Compos Struct 2001;54:121-6. technical note.

[18] Vinayak R, Prathap G, Naganarayana B. Beam elements based on a higher order theory - i. formulation and analysis of performance. Comput Struct 1996;58(4):775-89.

[19] Zhang Y, Kim K. A simple displacement-based 3-node triangular element for linear and geometrically nonlinear analysis of laminated composite plates. Comput Methods Appl Mech Eng 2005;194(45-47):4607-32.

[20] Heller R, Swift G. Solutions for the multilayer timoshenko beam. In: Report N VPI-E-71-12. Blacksburg (VA): Virginia Polytechnic Institute; 1971.

[21] Swift G, Heller R. Layered beam analysis. J Eng Mech ASCE 1974;100:267-82.

[22] Srinivas S. A refined analysis of laminated composites. J Sound Vib 1973:495-507.

[23] Whitney J. The effect of transverse shear deformation in the bending of laminated plates. J Compos Mater 1969;3:534-47.

[24] Pagano N. Exact solutions for composite laminates in cylindrical bending. J Compos Mater 1969;3:398-411.

[25] Shimpi R, Ainapure A. A beam finite element based on layerwise trigonometric shear deformation theory. Compos Struct 2001;53:153-62.

[26] Reddy J. On refined computational models of composite laminates. Int J Numer Methods Eng 1989;27:361-82.

[27] Pai P, Palazotto A. A higher-order sandwich plate theory accounting for a 3-d stresses. Int J Solids Struct 2001;38:5045-62.

[28] Ferreira A. Analysis of composite plates using a layerwise shear deformation theory and multiquadrics discretization. Mech Adv Mater Struct 2005;12: 99-112.

[29] Karger L, Wetzel A, Rolfes R, Rohwer K. A three-layered sandwich element with improved transverse shear stiffness and stresses based on fsdt. Comput Struct 2006;84:843-54.

[30] Mau S. A refined laminate plate theory. J Appl Mech ASME 1973;40:606-7.

[31] Murakami H. Laminated composite plate theory with improved in-plane responses. J Appl Mech ASME 1986;53:661-6.

[32] Carrera E. Layer-wise mixed models for accurate vibrations analysis of multilayered plates. J Appl Mech ASME 1998;65:820-8.

[33] Nguyen V-T, Caron J-F. A new finite element for free edge effect analysis in laminated composites. Comput Struct 2006;84:1538-46.

[34] Ambartsumyan S. Theory of anisotropic plates. In: Ashton JE, editor. Technomic Publishing Co.; 1969 [translated from Russian by T. Cheron]. 
[35] Sciuva MD. Bending, vibration and buckling of simply supported thick multilayered orthotropic plates: an evaluation of a new displacement model. J Sound Vib 1986;105:425-42.

[36] Bhaskar K, Varadan T. Refinement of higher-order laminated plate theories. AIAA J 1989;27:1830-1.

[37] Lee C-Y, Liu D, Lu X. Static and vibration analysis of laminated composite beams with an interlaminar shear stress continuity theory. Int J Numer Methods Eng 1992;33:409-24.

[38] Cho M, Parmerter R. Efficient higher-order composite plate theory for general lamination configurations. AIAA J 1993;31:1299-306.

[39] Averill R, Yip Y. Thick beam theory and finite element model with zig-zag sublaminate approximations. AIAA J 1996;34(8):1627-32.

[40] Aitharaju V, Averill R. $C^{0}$ zig-zag finite element for analysis of laminated composite beams. J Eng Mech ASCE 1999;125:323-30.

[41] Sciuva MD, Icardi U. Numerical assessment of the core deformability effect on the behavior of sandwich beams. Compos Struct 2001:52:41-53.

[42] Gaudenzi P, Barboni R, Mannini A. A finite element evaluation of single-layer and multi-layer theories for the analysis of laminated plates. Compos Struct 1995;30:427-40.

[43] Gherlone M, Sciuva MD. Thermo-mechanics of undamaged and damaged multilayered composite plates: a sub-laminates finite approach. Comput Struct 2007;81:125-36.

[44] Kapuria S, Dumir P, Ahmed A. An efficient higher order zigzag theory for composite and sandwich beams subjected to thermal loading. Int J Solids Struct 2003;40:6613-31.

[45] Carrera E. Developments, ideas and evaluations based upon the reissner's mixed theorem in the modeling of multilayered plates and shells. Appl Mech Rev 2001;54:301-29.

[46] Demasi L. Refined multilayered plate elements based on murakami zig-zag functions. Compos Struct 2005;70:308-16.

[47] Demasi L. $\infty^{6}$ mixed plate theories based on the generalized unified formulation. part iv: Zig-zag theories. Compos Struct 2009;87(3):195-205.

[48] Carrera E. Theories and finite elements for multilayered plates and shells: a unified compact formulation with numerical assessment and benchmarking. Appl Mech Rev 2003:10(3):215-96.

[49] Carrera E. On the use of the murakami's zig-zag function in the modeling of layered plates and shells. Comput Struct 2004;82:541-54

[50] Brischetto S, Carrera E, Demasi L. Improved bending analysis of sandwich plates using zig-zag function. Compos Struct 2009;89:408-15.

[51] Jing H, Tzeng K. Refined shear deformation theory of laminated shells. AIAA J 1993;31(4):765-73.

[52] Toledano A, Murakami H. A high-order laminated plate theory with improved in-plane responses. Int J Solids Struct 1987;23:111-31.

[53] Fernandes A. A mixed formulation for elastic multilayer plates. CR Acad Sci Paris 2003:331:337-42.

[54] Noor A, Burton W. Assessment of computational models for multilayered composite shells. Appl Mech Rev 1990;43(4):67-97.
[55] Reddy J. Mechanics of laminated composite plates - theory and analysis. Boca Raton, FL: CRC Press; 1997.

[56] Carrera E. Theories and finite elements for multilayered, anisotropic composite plates and shells. Arch Comput Methods Eng 2002;9:87-140.

[57] Zhang Y, Yang C. Recent developments in finite elements analysis for laminated composite plates. Compos Struct 2009;88:147-57.

[58] Touratier M. A generalization of shear deformation theories for axisymmetric multilayered shells. Int J Solids Struct 1992;29:1379-99.

[59] Ganapathi M, Patel B, Polit O, Touratier M. A $c^{1}$ finite element including transverse shear and torsion warping for rectangular sandwich beams. Int J Numer Methods Eng 1999;45:47-75.

[60] Polit O, Touratier M. A multilayered/sandwich triangular finite element applied to linear and nonlinear analysis. Compos Struct 2002;58:121-8.

[61] Touratier M. An efficient standard plate theory. Int J Eng Sci 1991;29:901-16.

[62] Touratier M. A refined theory of laminated shallow shells. Int J Solids Struct 1992;29(11):1401-15

[63] Dau F, Polit O, Touratier M. $C^{1}$ plate and shell finite elements for geometrically nonlinear analysis of multilayered structures. Comput Struct 2006;84:1264-74.

[64] Cheng S. Elasticity theory of plates and a refined theory. J Appl Mech ASME 1979;46:644-50

[65] Polit O, Touratier M. High order triangular sandwich plate finite element for linear and nonlinear analyses. Comput Methods Appl Mech Eng 2000;185:305-24.

[66] Vidal P, Polit O. A family of sinus finite elements for the analysis of rectangular laminated beams. Compos Struct 2008;84:56-72. doi:10.1016 i.compstruct.2007.06.009

[67] Polit O, Touratier M, Lory P. A new eight-node quadrilateral shear-bending plate finite element. Int J Numer Methods Eng 1994;37:387-411.

[68] Pagano N. Exact solutions for rectangular bidirectional composites and sandwich plates. J Compos Mater 1970;4:20-34.

[69] Vidal P, Polit O. A refined sine-based finite element with transverse normal deformation for the analysis of laminated beams under thermomechanical loads. J Mech Mater Struct 2009;4(6):1127-55.

[70] Karama M, Afaq K, Mistou S. Mechanical behaviour of laminated composite beam by the new multi-layered laminated composite structures model with transverse shear stress continuity. Int J Solids Struct 2003;40:1525-46.

[71] Karama M, Harb BA, Mistou S, Caperaa S. Bending, buckling and free vibration of laminated composite with a transverse shear stress continuity model. Compos Part B: Eng J 1998:29:223-34.

[72] Kapuria S, Dumir P, Jain N. Assessment of zigzag theory for static loading, buckling, free and forced response of composite and sandwich beams. Compos Struct 2004;64:317-27.

[73] Vidal P, Polit O. Vibration of multilayered beams using sinus nite elements with transverse normal stress. Compos Struct 2010;92:1524-34. doi:10.1016 